\title{
Erratum: Genomic inference of the metabolism of cosmopolitan subsurface Archaea, Hadesarchaea
}

Brett J. Baker, Jimmy H. Saw, Anders E. Lind, Cassandre Sara Lazar, Kai-Uwe Hinrichs, Andreas P. Teske and Thijs J. G. Ettema Nature Microbiology 1, 16002 (2016); published 15 February 2016; corrected 6 June 2016.

This Letter should have been published under a Creative Commons licence according to the Nature policy on publishing the primary sequence of an organism's genome for the first time. The editors apologize to the authors and to readers for this error. The manuscript is now open access and published under a CC-BY licence. All versions of the Letter have been modified accordingly. 